\title{
Significance of risk factor analysis and dissection for station 4L lymphatic metastasis in left lung cancer: a systematic review and meta-analysis
}

\author{
Chu-Xu Wang ${ }^{1,2 \#}$, Chun $\mathrm{Xu}^{1,2 \#}$, Chang $\mathrm{Li}^{1,2}$, Cheng Ding ${ }^{1,2}$, Jun Chen $^{1,2}$, Jun Zhao ${ }^{1,2}$ \\ ${ }^{1}$ Department of Thoracic Surgery, The First Affiliated Hospital of Soochow University, Medical College of Soochow University, Suzhou, China; \\ ${ }^{2}$ Institute of Thoracic Surgery, The First Affiliated Hospital of Soochow University, Suzhou, China \\ Contributions: (I) Conception and design: CX Wang, J Zhao; (II) Administrative support: J Zhao; (III) Provision of study materials or patients: J Zhao; \\ (IV) Collection and assembly of data: CX Wang; (V) Data analysis and interpretation: CX Wang; (VI) Manuscript writing: All authors; (VII) Final \\ approval of manuscript: All authors. \\ "These authors contributed equally to this work. \\ Correspondence to: Jun Zhao. Department of Thoracic Surgery, The First Affiliated Hospital of Soochow University, Medical college of Soochow \\ University, Suzhou 215000, China. Email: zhaojia0327@126.com.
}

Background: The effect of $4 \mathrm{~L}$ lymph node dissection on the prognosis of left lung cancer is currently controversial. Therefore, a meta-analysis was conducted to compare the difference in prognosis between the dissection group and the non-dissection group, and assess the independent risk factors for 4L lymphatic metastasis.

Methods: A systematic literature retrieval from PubMed, Embase and CNKI was conducted to identify relevant studies up to October, 5, 2020. The data concerning the overall survival (OS) rate, disease-free survival (DFS) rate, and risk factors for 4L lymphatic metastasis were extracted and analyzed.

Results: L10 lymphatic metastasis was an independent risk factor for positive $\mathrm{L} 4$ lymph node result ( $\mathrm{Z}=4.89$, $\mathrm{P}<0.05)$. The probability of positive L4 with positive L10 was 5.11 times of that with negative L10. L5 lymphatic metastasis was an independent risk factor for positive $\mathrm{L} 4$ lymph node result $(\mathrm{Z}=3.92, \mathrm{P}<0.05)$. The probability of positive L4 with positive L5 was 3.92 times of that with negative L5. L7 lymphatic metastasis was not an independent risk factor for positive L4 lymph node result. Positive L4 lymph node decreased the survival rate of relevant patients while $\mathrm{L} 4$ lymph node dissection increased the survival rate of relevant patients $(\mathrm{Z}=2.81, \mathrm{P}<0.05$ or $\mathrm{Z}=4.18, \mathrm{P}<0.05)$. Positive $\mathrm{L} 4$ lymph node reduced the $\mathrm{DFS}$ time of relevant patients while L4 lymph node dissection prolonged the DFS time of relevant patients $(\mathrm{P}<0.05, \mathrm{Z}=2.72)$.

Conclusions: If the intraoperative pathological examination indicates positive station $10 \mathrm{~L}$ lymph node, station 4L lymph node will be dissected, which may be a good choice at present. Positive L4 lymph node may reduce the survival time and DFS time of relevant patients while dissection of positive station 4L lymph node may prolong the survival time and DFS time of relevant patients. The intraoperative rapid frozen section pathological examination of station 10L lymph node may be a good choice.

Keywords: Non-small cell lung cancer (NSCLC); station 4L metastasis; lymph-node dissection; prognosis

Submitted Dec 01, 2020. Accepted for publication Feb 26, 2021.

doi: $10.21037 /$ tcr-20-3339

View this article at: http://dx.doi.org/10.21037/tcr-20-3339 


\section{Introduction}

Lung cancer is the leading cause of death for cancer worldwide, with non-small cell lung cancer (NSCLC) accounting for about $85 \%$ of all lung cancers reported in relevant literature $(1,2)$. Mediastinal lymphatic metastasis is the main diffusion pathways for lung cancer, and also one of the important factors influencing the prognosis of lung cancer patients (3). For patients with lung cancer, intraoperative lymphadenectomy can not only obtain accurate staging, which facilitates postoperative adjuvant treatment, but also improve local control rate and survival rate of relevant patients to a certain extent $(4,5)$. Standard procedures for NSCLC treatment include lobectomy and systematic mediastinal lymph node dissection. However, the degree of mediastinal lymph node exposure and resection is still controversial $(6,7)$. According to the NCCN guideline for the diagnosis and treatment of NSCLC, lymph nodes should be sampled from at least 3 station N2 or a systematic dissection of lymph nodes should be performed. For patients with left lung cancer, it is recommended to remove lymph nodes and surrounding soft tissues in stations $4 \mathrm{~L}$ and 5-9 (8). The International Association for the Study of Lung Cancer (IASLC) recommends that systematic lymph node dissection involves minimum resection of at least three mediastinal lymph node stations, including the subcarinal lymph node, but for patients with left side tumors, 4LLNS is not needed (9). The main reason for these differences may be that the neighboring relationship of aortic arch, recurrent laryngeal nerve, thoracic duct and station 4L lymph node increases the difficulty in resection of the lymph node station, as well as potential surgical risk, thus affecting the decision of thoracic surgeons on lymph node resection to some extent $(10,11)$. However, the $4 \mathrm{~L}$ lymph node dissection has still not been attached much importance. Therefore, we conducted the meta-analysis on the importance of $4 \mathrm{~L}$ lymph node dissection and the risk factors for its metastasis. We present the following article in accordance with the PRISMA reporting checklist (available at http://dx.doi.org/10.21037/tcr-20-3339).

\section{Methods}

\section{Search strategies}

A systematic literature search from PubMed, Embase and CNKI was conducted to determine relevant studies up to October 5, 2020. Data concerning overall survival (OS) rate, disease-free survival (DFS) rate, and risk factors for station
4L lymphatic metastasis were extracted and analyzed. The retrieval strategy is as follows: ((Carcinoma, NonSmall-Cell Lung[Title/Abstract]) OR (Carcinoma, Non Small Cell Lung[Title/Abstract])) OR (Carcinomas, NonSmall-Cell Lung[Title/Abstract])) OR (Lung Carcinoma, Non-Small-Cell[Title/Abstract])) OR (Lung Carcinomas, Non-Small-Cell[Title/Abstract])) OR (Non-Small-Cell Lung Carcinomas[Title/Abstract])) OR (Nonsmall Cell Lung Cancer[Title/Abstract])) OR (Non-Small-Cell Lung Carcinoma[Title/Abstract])) OR (Non Small Cell Lung Carcinoma[Title/Abstract])) OR (Carcinoma, NonSmall Cell Lung[Title/Abstract])) OR (Non-Small Cell Lung Cancer[Title/Abstract])) OR (Lung Cancer[Title/ Abstract])) OR (Cancer, Lung[Title/Abstract])) OR (Cancers, Lung[Title/Abstract])) OR (Lung Cancers[Title/ Abstract])) AND ((((Group 4 lymph nodes[Title/Abstract]) OR (4L Lymph Node[Title/Abstract])) OR (station 4L[Title/Abstract])) OR (((group four[Title/Abstract]) OR (four lymph node[Title/Abstract])) OR (station four[Title/ Abstract]))), my registration number is: CRD42020215646, You can log in to PROSPERO and access my records at https://www.crd.york.ac.uk/PROSPERO.

\section{Study selections}

Inclusion criteria: (I) RCT or observational studies comparing NSCLC patients in the dissection group and the non-dissection group; (II) data concerning OS rate, DFS rate, risk factors for station $4 \mathrm{~L}$ lymphatic metastasis; (III) in studies based on overlapping patients, the most recent or completed studies are included. Exclusion criteria: (I) papers without relevant data for extraction and analysis; (II) case reports, abstracts, meeting reports, reviews and experiments.

\section{Data extraction and quality assessment}

The two authors independently extracted data from the included studies and compared the results. Relevant differences were settled by third author, so as to avoid relevant bias. Relevant data were retrieved from complete articles using standardized data collection forms. Data collected for each study were as follows: the first author, the year of publication, the number of patients, the method for preoperative staging, age, study design, and follow-up time. The results included independent risk factors for OS, DFS, and lymphatic metastasis. Newcastle Ottawa Scale (NOS) was used for quality assessment and bias risk analysis in 
Table 1 Characteristics of the included studies in this meta-analysis

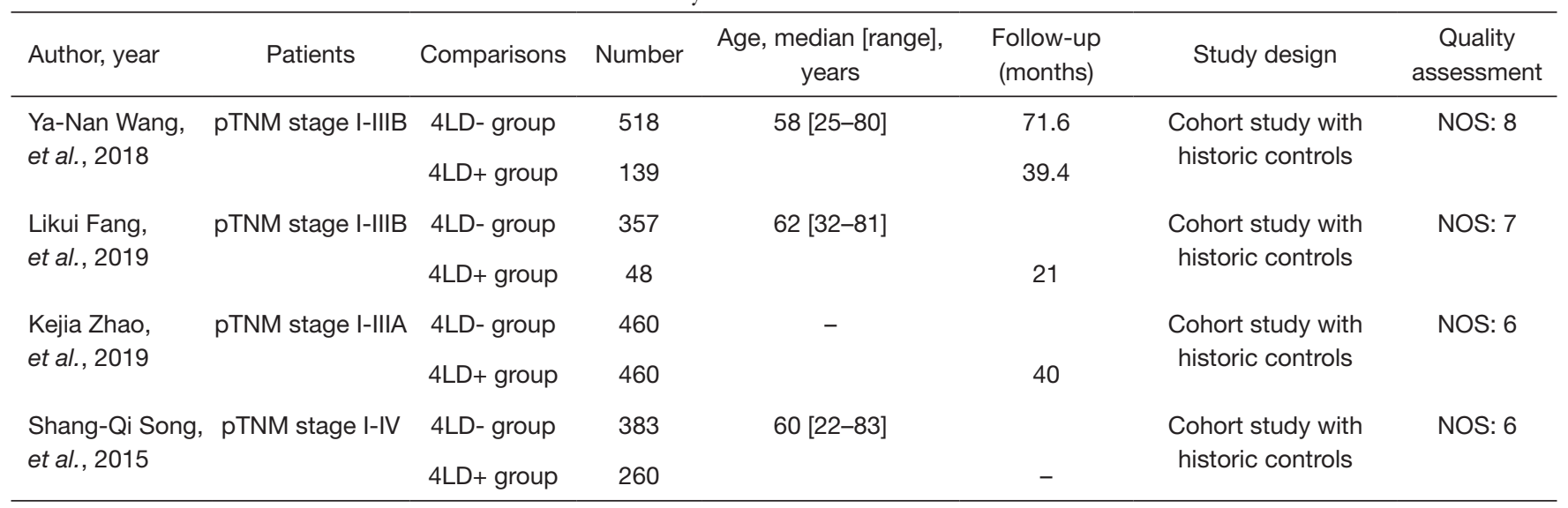

Table 2 Risk of bias assessment of the included cohort studies

\begin{tabular}{|c|c|c|c|c|c|c|c|c|c|}
\hline Author, year & \multicolumn{4}{|c|}{ Selection } & Comparability & \multicolumn{3}{|c|}{ Outcome } & Total score \\
\hline $\begin{array}{l}\text { Likui Fang, } \\
\text { et al., } 2019\end{array}$ & 论 & th & is & is & 糸 & is & ts & - & NOS: 7 \\
\hline $\begin{array}{l}\text { Kejia Zhao, } \\
\text { et al., } 2019\end{array}$ & 弥 & 拧 & 弥 & 场 & 㧒 & 弥 & - & - & NOS: 6 \\
\hline $\begin{array}{l}\text { Shang-Qi } \\
\text { Song, et al., } \\
2015\end{array}$ & tst & is & is & is & 论 & is & - & - & NOS: 6 \\
\hline
\end{tabular}

observational studies, and the scale included three factors: patient selection, comparability of the study groups, and assessment of results. Each study had a score ranged from 0 to 9 (assigned with *), and high-quality studies were defined as studies with a quality score up to 7 (Tables 1,2). The first author's name and the year of publication ARE were used for identification.

\section{Statistical analysis}

For all of the analyses, the Review Manager 5.3 software provided by the Cochrane Collaboration was used according to the PRISMA Guidance (12). For dichotomous data, such as OS and DFS, all 95\% CI risk ratios (RRs) were extracted directly from the text of studies or Kaplan-Meier curve. For each study, the heterogeneity between studies was evaluated based on $\mathrm{X}^{2} \mathrm{Q}$ test and $\mathrm{I}^{2}$ test. If the studies were highly heterogeneous $(\mathrm{P}<0.1)$, a random effect model was used. For others, a fixed effect model was used. Also, a sensitivity analysis may be performed through removal of studies one by one. Funnel plots were used to estimate potential publication bias. If $\mathrm{P}<0.05$, there was statistical significance.

\section{Results}

\section{Description of studies}

The analysis flow chart is as shown in Figure 1. After a preliminary search, a total of 173 papers were identified. We had four papers for evaluation in detail. Since there were few studies on station 4L lymph node, some data in this paper may be not so complete, and for this, we may use subgroup analysis. Among the papers, there was one without OS or DFS data, and one without independent 


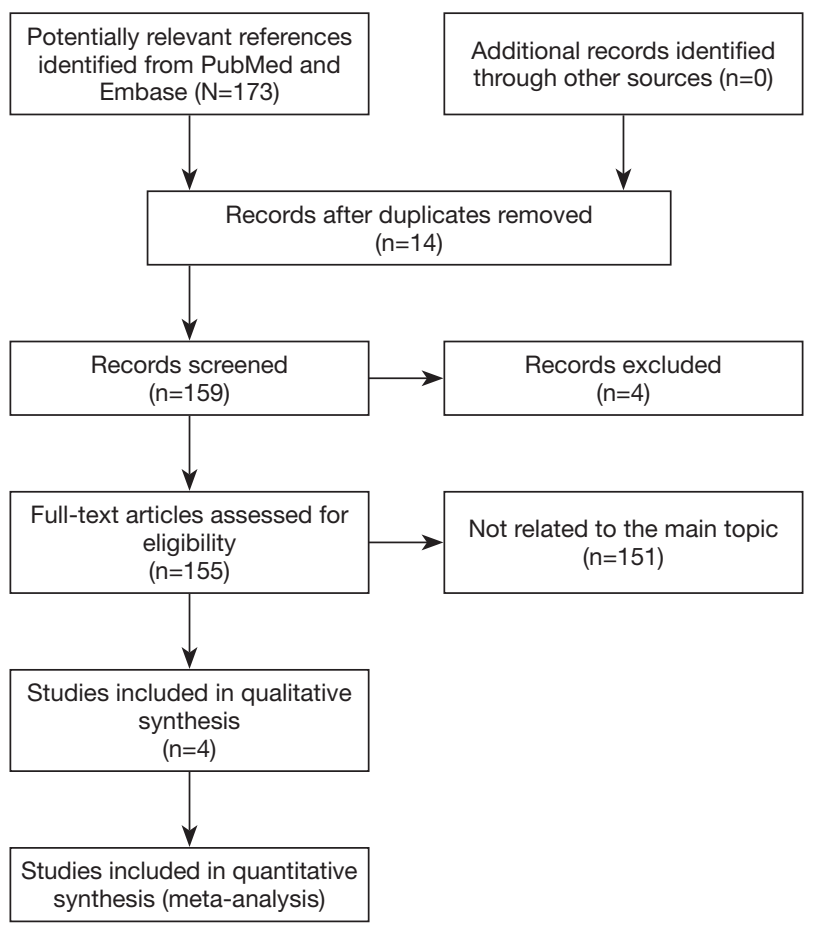

Figure 1 A flow chart showed the progress of trials through the review.

risk factor analysis on station 4L lymphatic metastasis. We found four articles without data of large bias. Finally, 4 retrospective cohort studies were included, and a total of 2,635 patients were analyzed. The main characteristics of patients in these studies were listed in Table 1. The staging of these patients was based on a postoperative pathological diagnosis. The two groups were comparable in average age. These, including the follow-up time, were as shown in Table 1. The patients were divided into $4 \mathrm{LD}^{-}$Group and $4 \mathrm{LD}^{+}$Group. In these cohort studies, four were compared using the same time periods and controls. Data analyzed in these studies included independent risk factors for OS, DFS, and positive 4L lymph node.

\section{Quality assessment and risk of bias}

For the included studies, relevant quality assessment and bias risk analysis were carried out. NOS scale was used to evaluate the following four articles, and the quality assessment of the included cohort studies was listed in Table 2. We rated a study with score above 7 as high quality, indicating low risk of bias. There was no follow-up time for one of the articles, but there was no bias because we excluded it from the subgroup study. One of the studies had a relatively short follow-up time, but relevant bias was acceptable. This will be detailed below.

\section{Meta-analysis of risk factor analysis for 4 L lymphatic metastasis}

A total of three articles analyzed the risk factors of $4 \mathrm{~L}$ lymphatic metastasis. A univariate analysis found many factors influencing 4L lymphatic metastasis. However, a multiple logistic regression analysis showed that the factors mentioned in three articles might involve positive 10L lymph node, positive $5 \mathrm{~L}$ lymph node, positive $7 \mathrm{~L}$ lymph node, and cN2. Positive 10L lymph node was considered as an independent risk factor for $4 \mathrm{~L}$ lymphatic metastasis in all of the three articles. Then, the Review Manager 5.3 software was used to map the forest and funnel plots. According to Figure 2, obviously, there was no heterogeneity in the study results, $\mathrm{I}^{2}=0 \%$. Therefore, a fixed effect model was selected for meta-analysis of L10 metastasis factors, and it was concluded that L10 lymphatic metastasis was an independent risk factor for positive L4 lymph node result $(\mathrm{Z}=4.89, \mathrm{P}<0.05)$. The probability of positive L4 with positive L10 was 5.11 times of that with negative L10. According to Figure 3, obviously, there 


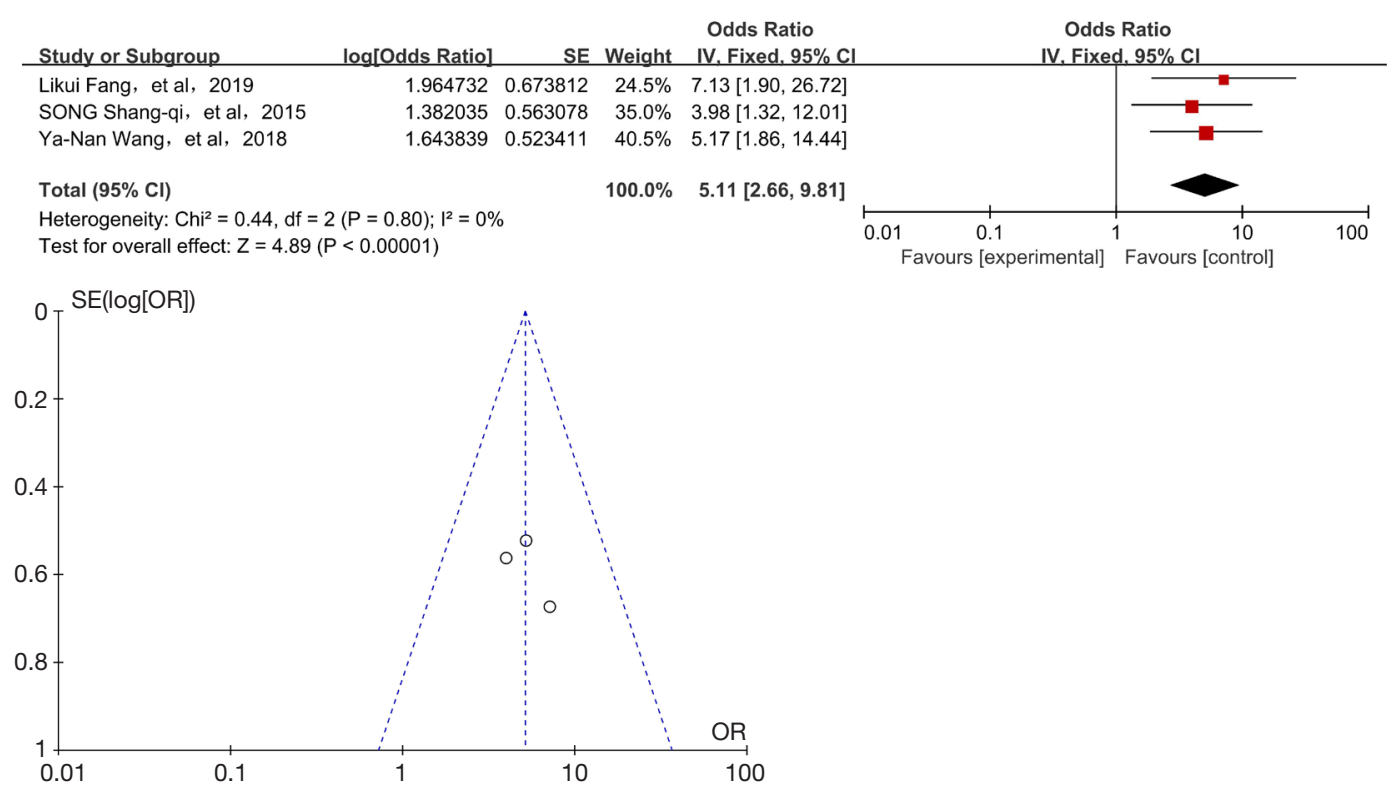

Figure 2 Funnel plot and forest plot of 10L lymph node.

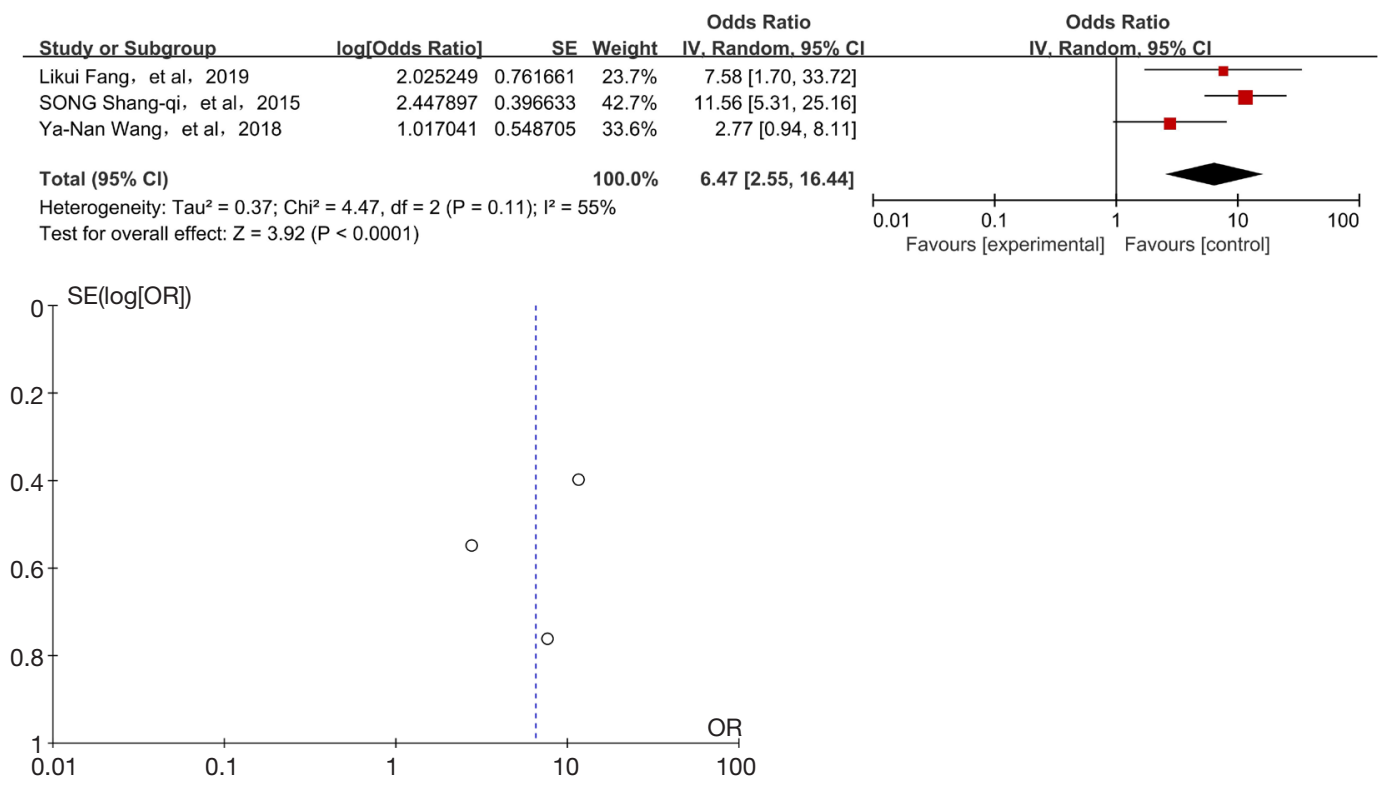

Figure 3 Funnel plot and forest plot of 5L lymph node.

was slight heterogeneity in the study results, $\mathrm{I}^{2}=55 \%$. Therefore, a random effect model was selected for Metaanalysis of L4 metastasis factors, and it was concluded that L5 lymphatic metastasis was an independent risk factor for positive $\mathrm{L} 4$ lymph node result $(\mathrm{Z}=3.92, \mathrm{P}<0.05)$. The probability of positive L4 with positive L5 was 3.92 times of that with negative L5. L7 lymphatic metastasis was not an independent risk factor for positive L4 lymph node result. When we extracted OR values for station 7 lymph node for statistical analysis, with the random effect model, we concluded that positive station 7 lymph node was not an independent risk factor for L4 lymphatic metastasis $\left(\mathrm{I}^{2}\right.$ value: $63 \%, \mathrm{P}=0.05)$. In a sensitivity analysis, after deleting the Song et al., 2015, we found from Figure 4 that there was 


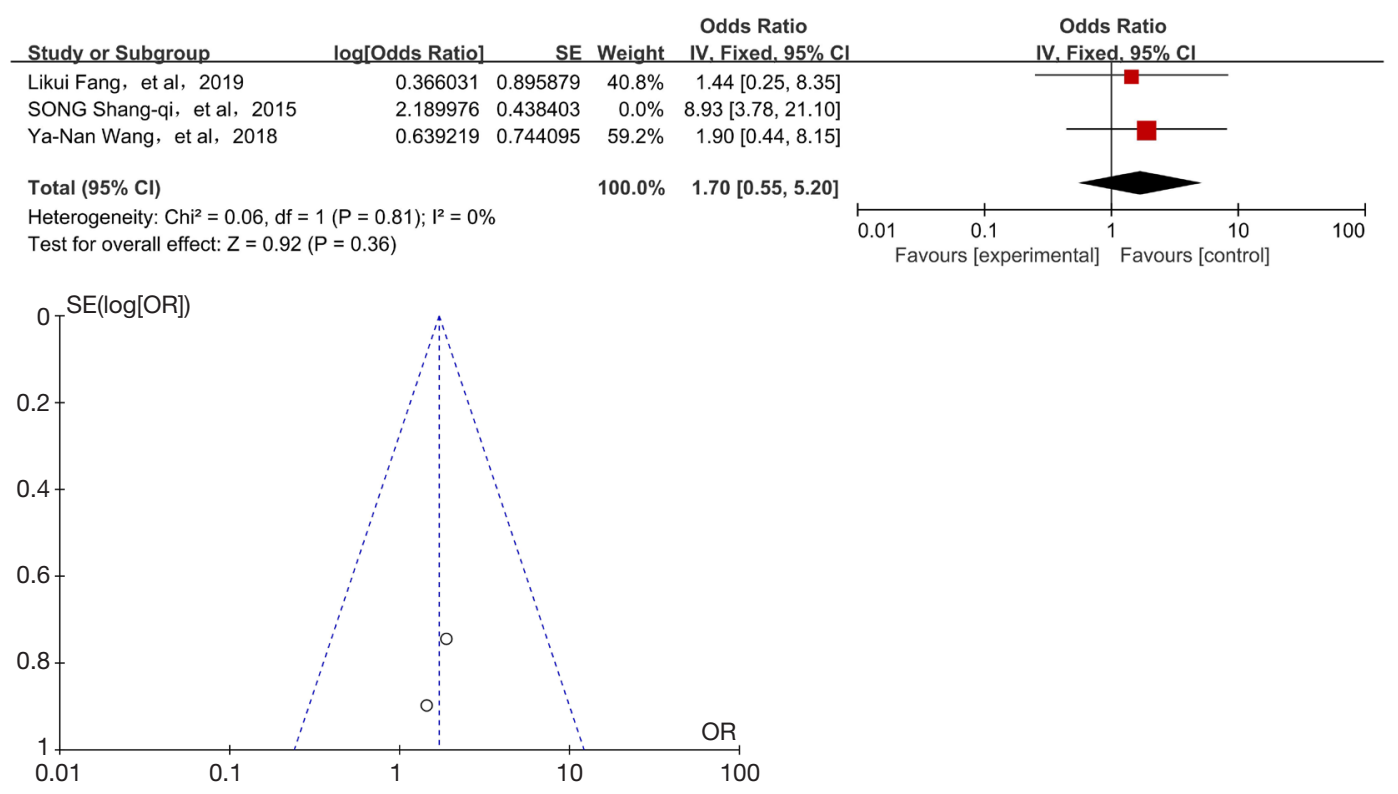

Figure 4 Funnel plot and forest plot of station 7 lymph node.

no heterogeneity in the study results, $\mathrm{I}^{2}=0 \%$. Therefore, a fixed-effect model was selected for Meta-analysis of L4 metastasis factors, and it was concluded that station 7 lymphatic metastasis was not an independent risk factor for positive L4 lymph node result ( $\mathrm{Z}=0.92, \mathrm{P}=0.36)$. Finally, we concluded that positive station 7 lymph node result was not an independent risk factor for L4 metastasis according to the above three articles.

\section{Meta-analysis of OS analysis for $4 L$ lymphatic metastasis}

A total of three articles followed up both the dissection group and the non-dissection group for the survival time. The results of multivariate analysis showed that the $4 \mathrm{~L}$ lymph node dissection was an independent risk factor influencing the prognosis of patients. According to Figure 5, obviously, there was heterogeneity in the study results, $\mathrm{I}^{2}=64 \%$. Therefore, the reasons of heterogeneity may also be further investigated through the random effect model. The reason for heterogeneity can be found in the article Fang et al., 2019, whose follow up time was relatively short. For meta- analysis results after deleting this article, see Figure 6. According to the above analysis results, both the random effect model and the fixed model showed that the positive L4 lymph node result reduced the survival rate of relevant patients, and the L4 lymph node dissection prolonged the survival time of relevant patients $(\mathrm{Z}=2.81$,
$\mathrm{P}<0.05$ or $\mathrm{Z}=4.18, \mathrm{P}<0.05)$. And we can infer that the evidence will become clearer with follow up time. However, that inference is to be supported with more data.

\section{Meta-analysis of DFS analysis for 4L lymphatic metastasis}

A total of three articles followed up the DFS. We extracted the $\mathrm{HR}$ value and $95 \% \mathrm{CI}$ from the three articles, and then drew the forest map and funnel map (Figure 7). According to the Figure 7, obviously, there was moderate heterogeneity in the study results, $\mathrm{I}^{2}=60 \%$. Therefore, when the random effect model was selected, the positive L4 lymph node result reduced the DFS time of relevant patients, and the L4 lymph node dissection prolonged the DFS time of relevant patients $(\mathrm{P}<0.05, \mathrm{Z}=2.72)$. According to a sensitivity analysis, the reason for heterogeneity were still from Fang et al., 2019, and the results might be caused by a short follow-up time, but this did not affect our conclusion.

\section{Discussion}

Metastasis of tumor cells is an important factor influencing the prognosis of relevant patients, and so, complete lymph node dissection is of great significance (13). However, with the development of thoracoscopy technology, more and more doctors want to reduce the number of lymph nodes dissection. For example, in a study of Okada et al., lymph 

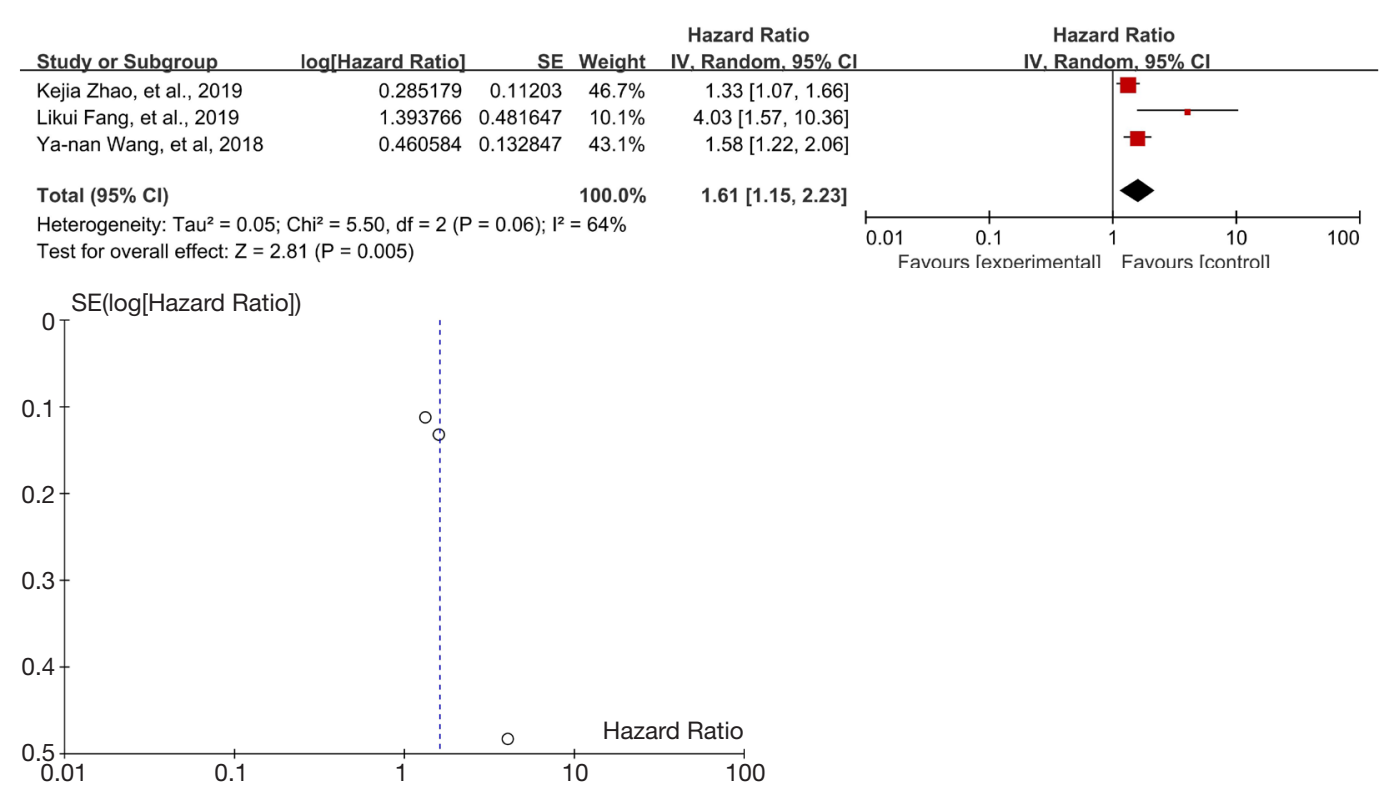

Figure 5 Forest map and funnel plot drawn for OS with random effect model. OS, overall survival.

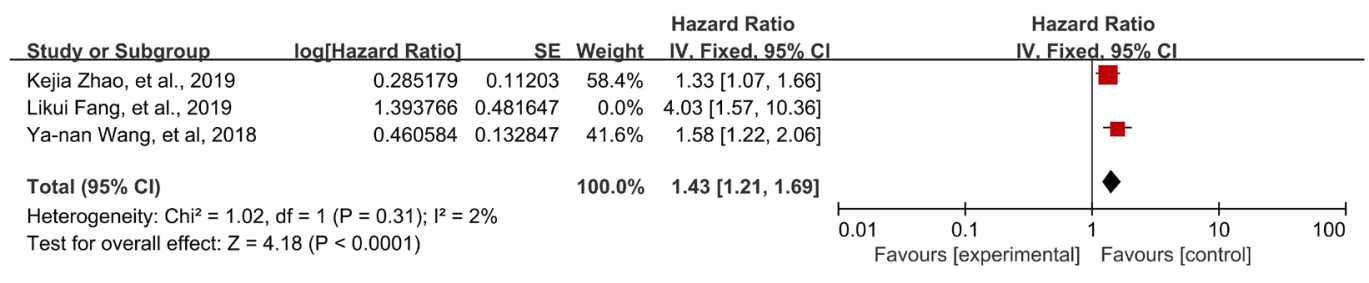

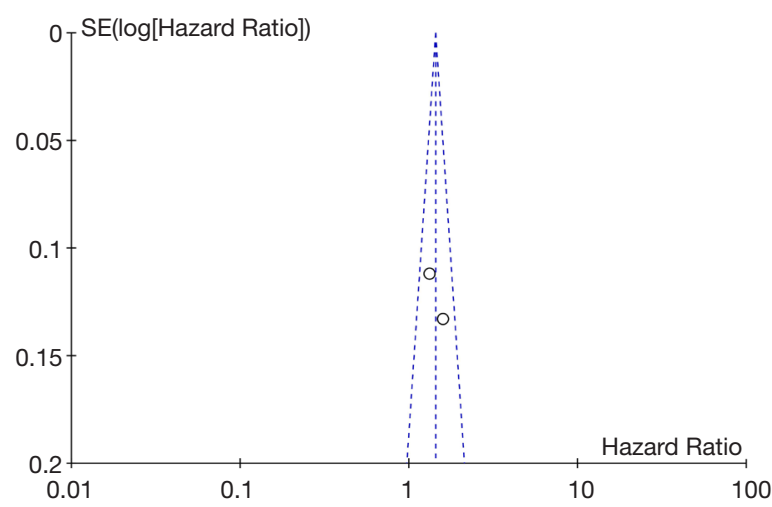

Figure 6 Forest map and funnel map drawn for OS after excluding one article through sensitivity analysis. OS, overall survival.

node dissection in the specific drainage area of the lung resulted in less trauma, but did not shorten the patients' survival time (14). However, in the study, the subjects were generally at early stage of NSCLC. For stage II or even higher stage of NSCLC, lymph node dissection can not only reduce the postoperative recurrence rate, but also provide more precise staging for patients, thus further supporting future medical treatment $(5,9)$. But what is a reasonable lymph node dissection? It has always been a hot topic for discussion among scholars. The IASLC recommends 3 lymph node stations for removal, including station 7 (9). However, Zurich Medical University 

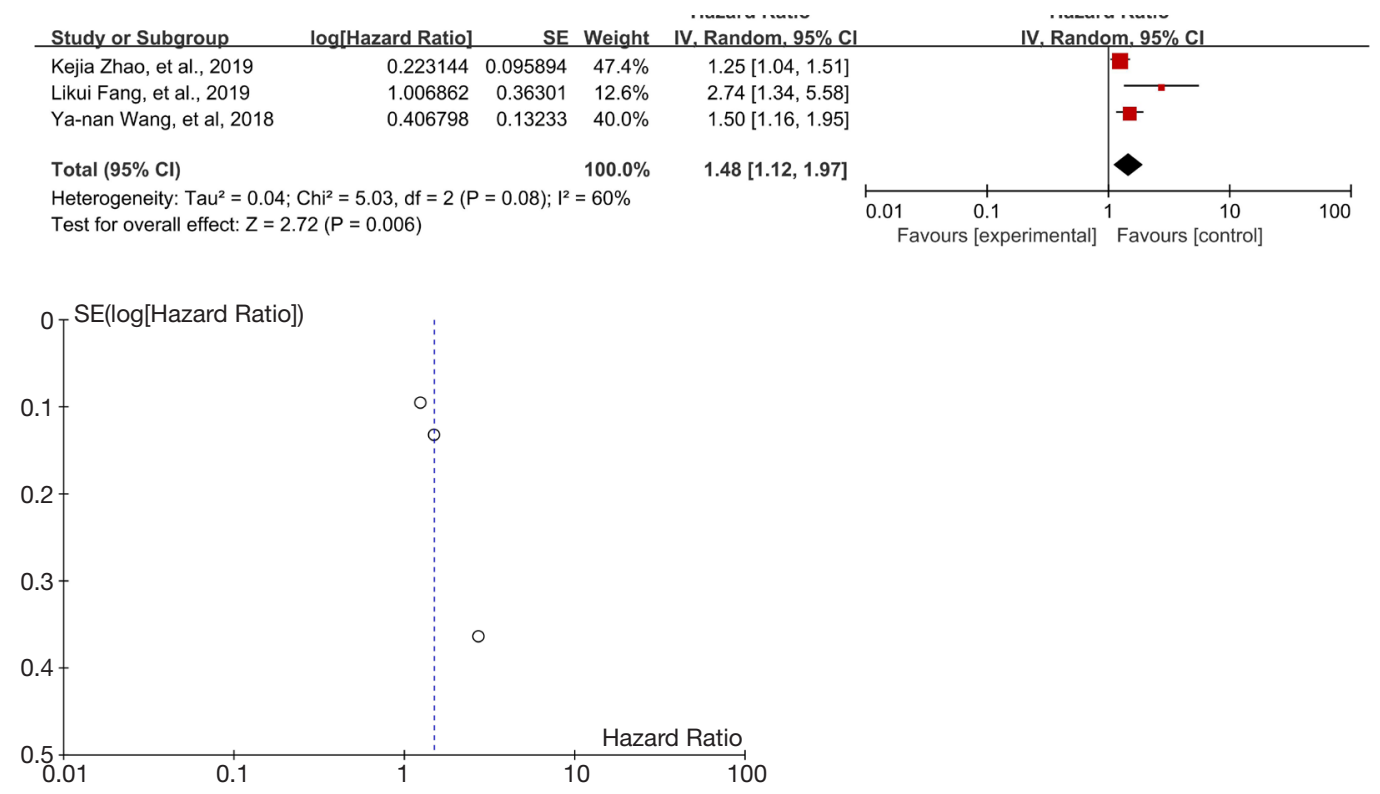

Figure 7 Forest map and funnel plot drawn 1 for DFS with random effect mode. DFS, disease-free survival.

emphasized that at least $4 \mathrm{~L}, 5$ and $6 \mathrm{LNS}$ should be excised for treatment of left side tumors (8). At the same time, Japanese researchers (Sakao et al.) pointed out that station 4LLND might have a beneficial effect on the prognosis of left lung cancer (15). An analysis showed that the reasons for relevant controversy might be as follows: complex anatomy of station $4 \mathrm{~L}$ : adjacent to the aortic arch, left recurrent laryngeal nerve, and thoracic duct. Dissection of the lymph nodes here may result in damage to the aortic arch, recurrent laryngeal nerve, or even the thoracic duct. These anatomical limitations make $4 \mathrm{~L}$ dissection more difficult and increase the surgical risk (16). Due to the communication relationship between station 7 lymph node and mediastinal lymph node, there were many relevant studies previously, but $4 \mathrm{~L}$ lymph node was often assigned to superior mediastinal lymph nodes $(17,18)$.

However, with the development of thoracoscopic technology, areas that were previously difficult to be exposed through routine surgery can now be identified and removed after magnified by thoracoscopy (19-21).

According to the above analysis, station $4 \mathrm{~L}$ lymph node dissection may be meaningful and feasible. Some previous studies have also pointed out the significance of station 4L lymph node dissection. However, as far as we know, no relevant meta-analysis has been conducted for this. In the four articles collected by us, three analyzed the risk factors of station $4 \mathrm{~L}$ lymphatic metastasis. According to the results of univariate analysis, there were many risk factors influencing lymphatic metastasis. For example, the metastasis of other lymph nodes may affect the $4 \mathrm{~L}$ lymph node metastasis and the tumor size. However, by a multivariate analysis, they all found positive left hilar lymph node result, which might be one of the independent risk factor for $4 \mathrm{~L}$ lymphatic metastasis (22-24). This is consistent with our conclusion, which provides thoracic surgeons an indication: The intraoperative rapid frozen section pathological examination of station 10L lymph node may be a good choice. If the intraoperative pathological examination indicates positive station 10L lymph node result, station $4 \mathrm{~L}$ lymph node dissection will be performed, which may be a good choice at present. Three articles $(22,23,25)$ followed up DFS and OS for observation, and the follow up time of Wang et al. (22). was relatively long. Furthermore, the tendency score weighting method was adopted to reduce the confounding effects observed between the two groups. Based on the above articles, we conducted a meta-analysis and reached a conclusion consistent with them, which further indicated the importance of the $4 \mathrm{~L}$ lymph node dissection. At the same time, some articles pointed out that positive station $5 \mathrm{~L}$ lymph node result was also an independent risk factor for station $4 \mathrm{~L}$ lymphatic metastasis, which needs to be further confirmed by more RTC studies (23).

Of course, some scholars believed that there were many problems with these findings. For example, De Ruysscher 
et al. raised some questions in their study. First, considering the anatomical limitations of station $4 \mathrm{~L}$ lymph node, was the rate of incomplete resection higher than that of other stations of lymph nodes? An indirect method for assessing the incomplete resection rate is to observe the recurrence pattern of stage III NSCLC after surgery. If the incomplete resection rate of station $4 \mathrm{~L}$ is higher than that of other stations, a higher local recurrence rate can be reasonably predicted. However, this has not been observed (26,27). Local recurrence after left lung cancer surgery did not occur at station $4 \mathrm{~L}$ for the most part. Instead, local recurrence occurred at stations $4 \mathrm{R}$ and 7 . Their study suggested that whether station $4 \mathrm{~L}$ lymph node removal increases OS was more difficult to prove. In fact, the randomized Phase III trial did not show any effect of systemic or pulmonary lobe -specific lymph node dissection on OS although more patients developed to stage N2 disease and thus had indications for adjuvant chemotherapy. Wang et al. (22) found that surgical $4 \mathrm{~L}$ lymph node removal might improve OS, but this should only be taken as a hypothesis. As what the authors pointed out, their study was retrospective, and there was a significant imbalance of prognostic factors between the group receiving station $4 \mathrm{~L}$ lymph node dissection and another group. Propensity techniques are an attempt to deal with imbalance of mixed factors, but they are nothing like randomization (28). Therefore, the bias caused by non-simultaneous station $4 \mathrm{~L}$ lymph node dissections cannot be eliminated effectively. But in the end, the scholar believed that the study of Wang et al. was positive even though they could not confirm whether station 4L lymph node had a real effect on OS or not. However, for station 10L lymphatic metastasis, local radiotherapy should be performed, but the dose for radiation is still to be determined. When $4 \mathrm{~L}$ lymphatic metastasis is definite, radiotherapy and chemotherapy should be given.

Reinersman (29) believed that focusing on survival rate after lymphadenectomy was a false dualism. We should not only focus on whether $4 \mathrm{~L}$ lymph node dissection has therapeutic value, but also consider what the best evaluation on $4 \mathrm{~L}$ lymph node station and other stations is. The Z0030 trial suggested that the most important was to consider how to assess mediastinal lymph nodes better and more thoroughly, rather than to consider the influence of lymphadenectomy degree on the survival rate. An improved assessment can make pathological staging more accurate (30). Therefore, he believed that it was incorrect to evaluate the prognosis of relevant patients simply with lymph node. What is really significant is not the survival advantage of lymphadenectomy itself, but the more accurate pathological staging. Further long-term randomized studies may put an end to these controversies.

There are some limitations in our study because relevant articles available for selection is limited, for there are still few similar studies at present. Considering that all of the above articles are of retrospective study and RCT studies are short, our conclusion is to be supported by more prospective RCT studies. In addition, there are some problems in the above studies, e.g., lack of follow up to different degrees and short follow-up time in some studies. These problems may be further solved by prospective RCT studies.

\section{Acknowledgments}

Funding: This study was funded by the National Natural Science Foundation of China (81672934 to J Zhao, 81873417 to $\mathrm{C} \mathrm{Li}, 81602704$ to $\mathrm{C} \mathrm{Xu})$.

\section{Footnote}

Reporting Checklist: The authors have completed the PRISMA reporting checklist. Available at http://dx.doi. org/10.21037/tcr-20-3339

Peer Review File: Available at http://dx.doi.org/10.21037/tcr20-3339

Conflicts of Interest: All authors have completed the ICMJE uniform disclosure form (available at http://dx.doi. org/10.21037/tcr-20-3339). The authors have no conflicts of interest to declare.

Ethical Statement: The authors are accountable for all aspects of the work in ensuring that questions related to the accuracy or integrity of any part of the work are appropriately investigated and resolved.

Open Access Statement: This is an Open Access article distributed in accordance with the Creative Commons Attribution-NonCommercial-NoDerivs 4.0 International License (CC BY-NC-ND 4.0), which permits the noncommercial replication and distribution of the article with the strict proviso that no changes or edits are made and the original work is properly cited (including links to both the formal publication through the relevant DOI and the license). See: https://creativecommons.org/licenses/by-nc-nd/4.0/. 


\section{References}

1. Torre LA, Bray F, Siegel RL, et al. Global cancer statistics, 2012. CA Cancer J Clin 2015;65:87-108.

2. Herbst RS, Heymach JV, Lippman SM. Lung cancer. N Engl J Med 2008;359:1367-80.

3. Vansteenkiste J, De Ruysscher D, Eberhardt WE, et al. Early and locally advanced non-small-cell lung cancer (NSCLC): ESMO Clinical Practice Guidelines for diagnosis, treatment and follow-up. Ann Oncol 2013;24 Suppl 6:vi89-98.

4. Friedel G, Linder A, Pfeiffer S, et al. Radical lung surgery interventions with special reference to lymphadenectomy. Langenbecks Arch Chir Suppl Kongressbd 1996;113:785-9.

5. Lardinois D, Suter H, Hakki H, et al. Morbidity, survival, and site of recurrence after mediastinal lymph-node dissection versus systematic sampling after complete resection for non-small cell lung cancer. Ann Thorac Surg 2005;80:268-74; discussion 274-5.

6. Wu Y, Huang ZF, Wang SY, et al. A randomized trial of systematic nodal dissection in resectable non-small cell lung cancer. Lung Cancer 2002;36:1-6.

7. Darling GE, Allen MS, Decker PA, et al. Number of lymph nodes harvested from a mediastinal lymphadenectomy: results of the randomized, prospective American College of Surgeons Oncology Group Z0030 trial. Chest 2011;139:1124-9.

8. Mohler JL, Antonarakis ES, Armstrong AJ, et al. Prostate Cancer, Version 2.2019, NCCN Clinical Practice Guidelines in Oncology. J Natl Compr Canc Netw 2019; 17:479-505.

9. Rami-Porta R, Wittekind C, Goldstraw P. Complete resection in lung cancer surgery: proposed definition. Lung Cancer 2005;49:25-33.

10. Hirono T, Yamato Y, Souma T, et al. How extensive should lymph node dissection be done for the surgery of the left lung cancer? Kyobu Geka 1994;47:20-3.

11. Hata E, Miyamoto H, Sakao Y. Investigation into mediastinal lymph node metastasis of lung cancer and rationale for decision of the extent of mediastinal dissection. Nihon Geka Gakkai Zasshi 1997;98:8-15.

12. Moher D, Liberati A, Tetzlaff J, et al. Preferred reporting items for systematic reviews and meta-analyses: the PRISMA statement. PLoS Med 2009;6:e1000097.

13. Watanabe S. Lymph node dissection for lung cancer: past, present, and future. Gen Thorac Cardiovasc Surg 2014;62:407-14.
14. Okada M, Sakamoto T, Yuki T, et al. Selective mediastinal lymphadenectomy for clinico-surgical stage I non-small cell lung cancer. Ann Thorac Surg 2006;81:1028-32.

15. Sakao Y, Miyamoto H, Yamazaki A, et al. The spread of metastatic lymph nodes to the mediastinum from left upper lobe cancer: results of superior mediastinal nodal dissection through a median sternotomy. Eur J Cardiothorac Surg 2006;30:543-7.

16. Witte B, Hürtgen M. Video-assisted mediastinoscopic lymphadenectomy. Multimed Man Cardiothorac Surg 2007;2007:mmcts.2006.002576.

17. Aokage K, Yoshida J, Ishii G, et al. Subcarinal lymph node in upper lobe non-small cell lung cancer patients: is selective lymph node dissection valid? Lung Cancer 2010;70:163-7.

18. Okada M, Tsubota N, Yoshimura M, et al. Proposal for reasonable mediastinal lymphadenectomy in bronchogenic carcinomas: role of subcarinal nodes in selective dissection. J Thorac Cardiovasc Surg 1998;116:949-53.

19. Kim HJ, Kim YH, Choi SH, et al. Video-assisted mediastinoscopic lymphadenectomy combined with minimally invasive pulmonary resection for left-sided lung cancer: feasibility and clinical impacts on surgical outcomes†. Eur J Cardiothorac Surg 2016;49:308-13.

20. Nagashima T. Thoracoscopic left mediastinal lymph node dissection. Ann Transl Med 2016;4:10.

21. Liu J, Cui F, Li SB. Radical treatment for left upper-lobe cancer via complete VATS. J Thorac Dis 2013;5:868-72.

22. Wang YN, Yao S, Wang CL, et al. Clinical Significance of 4L Lymph Node Dissection in Left Lung Cancer. J Clin Oncol 2018;36:2935-42.

23. Fang L, Wang L, Wang Y, et al. Predictors and survival impact of station 4L metastasis in left non-small cell lung cancer. J Cancer Res Clin Oncol 2019;145:1313-9.

24. Song S, Liu C, Guo C, et al. Status and Risk Factors Analysis on 4L Lymphatic Metastasis in Lung Cancer. Chinese Journal of Clinical Thoracic and Cardiovascular Surgery 2015;22:1100-3.

25. Zhao K, Wei S, Mei J, et al. Survival Benefit of Left Lower Paratracheal (4L) Lymph Node Dissection for Patients with Left-Sided Non-small Cell Lung Cancer: Once Neglected But of Great Importance. Ann Surg Oncol 2019;26:2044-52.

26. De Ruysscher DKM, Decaluwé H. 4L Lymph Node Involvement in Left-Sided Lung Cancer: Unique or Not? J Clin Oncol 2018;36:2907-8.

27. Endoscopic and Endobronchial Ultrasonography According to the Proposed Lymph Node Map Definition 
in the Seventh Edition of the Tumor, Node, Metastasis Classification for Lung Cancer. J Thorac Oncol 2009;4:1576-84.

28. Kim DH, Pieper CF, Ahmed A, et al. Use and Interpretation of Propensity Scores in Aging Research: A Guide for Clinical Researchers. J Am Geriatr Soc 2016;64:2065-73.

29. Reinersman JM. Better Survival After 4L Lymph Node
Dissection for Early-Stage, Left-Sided, Non-small Cell Lung Cancer: Are We Debating a False Duality? Ann Surg Oncol 2019;26:1959-60.

30. Osarogiagbon RU, Decker PA, Ballman K, et al. Survival Implications of Variation in the Thoroughness of Pathologic Lymph Node Examination in American College of Surgeons Oncology Group Z0030 (Alliance). Ann Thorac Surg 2016;102:363-9.

Cite this article as: Wang $\mathrm{CX}, \mathrm{Xu} \mathrm{C}, \mathrm{Li} \mathrm{C}$, Ding C, Chen J, Zhao J. Significance of risk factor analysis and dissection for station 4L lymphatic metastasis in left lung cancer: a systematic review and meta-analysis. Transl Cancer Res 2021;10(4):1656-1666. doi: $10.21037 /$ tcr-20-3339 